\title{
O problema da técnica e a urgência do mistério
}

\section{Lisandra C. de Araújo Lima Teixeira ${ }^{1}$}

\author{
1 Mestranda no Programa de pós- graduação em Filosofia da Universidade Federal da Paraíba (UFPB). Bacharel em Relações Internacionais pela \\ Universidade Estadual da Paraíba (UEPB). \\ E-mail: lisandra@tutanota.de. Orcid: https://orcid.org/0000-0002-7904-7746
}

RESUMO: O artigo propõe analisar o problema da técnica moderna trabalhada pelo filósofo alemão Martin Heidegger em sua crítica a modernidade e à metafísica, elencando a questão da verdade, para Heidegger: alétheia. A questão da técnica nos leva a problemática de sua própria essência ge-stell, interpelação, onde o homem é posto para tudo dispor de forma unidimensional, a natureza é forçada a se mostrar como reserva, estoque, se configura como uma forma de domínio e controle, de acordo com sua demanda meramente econômica, científica, comercial, o próprio ser em sua essência é esquecido. O homem se coloca como sujeito para exploração desse objeto. O artigo tem como método a análise filosófica de obras heideggerianas, sob objetivo de indagar sobre a essência da técnica moderna como interpelação (Ge-stell) que nos leva a um crescente perigo do esquecimento do ser, e, também, da degradação da própria natureza tida como mero objeto de armazenamento de recursos; assim como refletir sobre a necessidade do mistério como faceta constituinte da verdade do ser como alétheia, desvelamento, como forma de dar um passo atrás em relação à modernidade e sua visão matemático/ científica, elevando o pensamento meditativo como originário e essencial. $\mathrm{O}$ artigo conclui que é necessário repensar nossa lida moderna com o próprio habitar, de forma a dar um salto da lógica tecnicista, onde se encontra o perigo, e estando no mesmo local des-velar um habitar mais próprio, autêntico.

Palavras-chave: Técnica. Existência. Verdade. Mistério.

ABSTRACT: The article proposes to analyze the problem of the modern technique thought by the German philosopher Martin Heidegger in his critique of the modernity and metaphysics, listing the question of truth, not metaphysics, for Heidegger: alétheia. The question of technique leads us to the problem of its own essence, ge-stell, interpellation, the world, the human being and nature are forced to show themselves as reserves, stocks, according to their purely economic, scientific, commercial demand. The own being in its essence is forgotten. The article has as method the bibliographical analysis of Heideggerian works, aiming to inquire about the essence of modern technique as interpellation (ge-stell) that leads us to a growing danger of the forgetting of being and also of the degradation of nature itself, considered as a mere resource of storage; as well as reflecting on the necessity of mystery as a constituent facet of the truth of being as alétheia, unveiling, as a way of stepping back from modernity and its scientific mathematical view, elevating meditative thinking as of considerable importance. The article concludes the need to rethink our modern deal with dwelling itself, so as to take a leap from the technicist logic, where danger lies, and being in the same place to unveil a more proper, authentic dwelling.

Keywords: Technique. Existence. Truth. Mystery.

O problema da técnica pensado por Martin Heidegger se faz atualmente de crescente importância e urgência a ser analisado. No mundo onde se encara uma maior separação do homem de um habitar autêntico, numa sociedade de massa que encara o desequilibrio social e ambiental. A hegemonia do cientificismo técnico moderno refletido na instituição da ciência moderna, o falatório cotidiano, nos leva a um 
perigo cada vez maior para o homem como reflexo do esquecimento do ser.

Em sua filosofia que já nos alerta e analisa essa problemática, Heidegger nos propõe uma forma de reparação que aos poucos possa retomar o saber da essência da técnica moderna. Em sua problematização da metafísica, contínuo esquecimento do ser, há a necessidade de escutar o apelo do ser para questionar realmente qual a origem deste esquecimento.

Heidegger propõe, então, um retorno ao antigo sentido detechnégrega voltada para o cuidado e para o respeito ao próprio desvelar das coisas como vêm ao encontro. Podemos pôr em um sentido ambiental atual e ampliar também o significar de cuidado para onde fazemos nossa morada, na diversidade da vida a se preservar, enquanto humano e/ou natureza (extra-humana).

A planetarização da técnica ou europeização, é um projeto que parte do continente europeu para o resto do planeta, como aborda Heidegger em sua carta resposta ao professor Dr. TakehikoKojima da Universidade de Tóquio (HEIDEGGER apud STEIN, 1965). Esse projeto combate a criação do desvelar autêntico, onde se encontraria o reparo que ultrapassaria o viés meramente científico de visão de mundo, mecanicista e matemático, focando no próprio cuidado do habitar autêntico, que veria o mundo além de fonte de energia e matéria prima bruta a ser lapidada em prol do progresso da técnica, da ciência e do mercado.

Heidegger propõe desenvolver e des-velar um caminho capaz de renovar e repensar o próprio ser para trazer o que se encontra na nossa própria frente e que somos incapazes de enxergar sua abertura. Aquilo que nos é mais próximo caiu no esquecimento, é necessário dar um salto, porém na mesma posição, um recuo, para o ainda não pensado.

Visar a questão do ser, compreendê-la é uma forma de se aproximar de sua verdade. Para Heidegger o ente que formula a questão, que questiona o próprio ser, é o dasein (ser-ấ), ele é o centro da questão do sentido do Ser. Sua compreensão (Verstehen) é característica unívoca do dasein, na procura daquilo que nos é mais próximo. A essência desse Ser-aí é seu estar jogado no mundo (Geworfenheit), ser-no-mundo (inder-welt-sein). Existir é ser no mundo com outros (mitdasein). A compreensão do ser é característica fundamental da existência humana.

A existência na filosofia heideggeriana tem como ponto central a temporalidade e finitude humana e o horizonte da morte é parte primordial dessa analítica da existência. A essência desse homem que compreende o ser é seu próprio existir, o qual o ser se revela previamente para o dasein, e esse é produto dessa revelação, é seu existir, ele é o ser, verbo, um entre no aberto. Ser-aí é o ente que compreende o ser na sua existência e finitude.

Em sua existência no mundo com os outros, é chamado ao manuseio das coisas. O homem é assim um já lançado (Geworfenheit) e entregue, já se encontra na queda cotidiana. Na sua insistência na constante fuga da morte para a vivência no a-gente (das man), onde a morte nunca é sua, mas do outro distante. Aí se encontra então uma existência inautêntica em fuga. Compreende-se apenas pela sua ocupação/ papel social, perde-se nas coisas fugindo para o a- gente, onde encontra conforto para sua fuga do horizonte da morte e de sua angústia.

Ele vê no falatório cotidianouma existência longe da angústia gerada pelo horizonte da morte, vista como trágica e sempre distante, a morte é sempre "a morte dos outros". Na fuga de sua finitude própria, em direção ao 'reino do Nós', o homem é ‘jogado' na cotidianidade mais comum, na vivência do esquecimento de seu próprio ser, onde impera falatório, que nada se conhece essencialmente, é sempre uma repetição de falas.

Em um de seus textos fundamentais $A$ essência da verdade (HEIDEGGER, 1930) o filósofo põe que 
uma verdade, diferente de como é posta no conceito moderno, não é advinda de um experimento prático, científico, técnico, político, da fé ou até mesmo de uma meditação filosófica. Ela afasta tudo sobre o que se caracteriza verdade na metafísica moderna. É diverso do cálculo, muitas vezes da lógica, da opinião comum do que é imediatamente útil, se afastando, então, a questão da verdade dessas exigências.

A verdade, de fato, não tem sua morada na enunciação, como o entendido comum põe verdade como adequação da coisa com enunciado, e sim na abertura que se realiza a essência da verdade. Ser livre no aberto para aquilo que está manifesto no aberto, que vem a se manifestar. A própria liberdade é essência da verdade. Não é uma liberdade reduzida à subjetividade humana, sua essência está além do homem. Porém, é para o dasein que a essência da liberdade se revela. Diferente do senso comum, não é ausência de constrangimento em relação a uma ação ou não, é, na verdade, abandono ao desvelamento do ente enquanto tal, é o "aî', o que permite ao homem existir.

Liberdade como deixar-ser para aquilo que é manifesto no aberto deixando que cada ente seja o ente que ele é, o ser enquanto ser, estar num relacionamento livre com aquilo que acena. Deixar-ser não como indiferença, mas como entrega ao aberto para o que cada ente traz consigo, desvelando e recuando frente a ele, para que ele se mostre como realmente é. Deixar- ser o ente se chama liberdade.

Verdade no sentido de liberdade tem caráter de alétheia, desvelamento original grego. Diferente do que foi posto na técnica, no controle da verdade por experiências e provas, onde as coisas não são permitidas a se mostrarem como são, mas por um viés científico/técnico, assim não se conhece originariamente o que é verdadeiro, apenas se dissimula e controla. Tudo quer assegurar e dominar, não permitindo ser o ente aquilo que ele é, dissimula, a aparência domina, não se conhece essencialmente e fundamentalmente, tudo é repetição de fala.

Deixar-ser o ente como é, é o não controle, libera o homem para sua própria verdade. Apenas esse tipo de liberdade desvelaria o homem para sua relação com o ente enquanto tal, para o desvelamento, alétheia. Não é a proposição vinda de um sujeito para um objeto, como dois entes, é verdadeiramente descobrir. O homem não existe aí sem essa liberdade. A capacidade técnica nada sabe da verdade, o ser é só dissimulado e controlado sob forma de experimentos, teorias, há dominação e controle, tudo conhece, encobrindo o ente em sua totalidade.

A insistência na dissimulação, no encobrimento, na não essência da verdade, impede o desvelamento próprio, o mistério, que é parte constitutiva da essência da verdade e de sua não essência é esquecido. Essa não essência da verdade, no entanto, é o próprio mistério constitutivo do aberto inexplorado do ser, o velar também é um acontecimento fundamental para a ocorrência da verdade, do desvelamento (alétheia).

Porém, quando impera o encobrimento como fundamento cai no esquecimento o ser e o mistério. O homem acaba por se distrair em suas próprias criações, enche de vontades e cálculos, sem a serenidade, meditação das essências, dos fundamentos próprios, o homem moderno técnico/ cientifico acaba, então, iludido em uma cadeia de pensamentos. O perigo, para Heidegger como aborda em Serenidade (HEIDEGGER, 1959) do alemão Gelassenheit, se encontra onde a dominação do senso comum e científico põe como inquestionável o ente manifesto, quando o próprio mistério é esquecido pela busca pelo progresso pela modernidade.

O perigo continua a existir na medida que o homem existe se afastando do mistério, da verdade do ser, para a agitação do mundo. Ele se mantém na errância, na queda da cotidianidade, no falatório, na curiosidade, na ambiguidade, no impessoal. Entretanto, isso faz parte de sua própria constituição de ser, fundamento para sua própria abertura e compreensão. Nasce da queda também (Verfallen) sua possibilidade 
mais própria da existência.

O movimento da physis de velamento e desvelamento, mostra a própria essência da verdade na qual apenas o ser-aí pode adentrar na verdade das coisas em sua relação com o ser a partir de sua projeção-aí transcendente. O pensamento técnico elimina a relação própria com o ser e se contrapõe ao pensamento meditativo sereno posto por Heidegger em Serenidade, que está sendo perdido e esquecido na modernidade metafísica pela interpretação meramente técnica do pensamento.

O pensamento técnico/científico para Heidegger é o final de um caminho metafísico percorrido a partir de Platão e Aristóteles e que desembocou na técnica e ciência moderna. A interpretação técnica do pensamento tem como sua essência Ge-stell, que significa interpelação \provocação. Esse pensamento afasta a verdade do Ser, é organizado de uma forma diferente e aplicado nas instituições científicas modernas, como põe Heidegger em A questão da técnica (HEIDEGGER, 1959).

O pensamento técnico é encontrado em todos os âmbitos. O ser da ciência como ciência moderna se configura na essência da técnica, na tentativa de formar uma teoria do real tendo por objeto a própria realidade. A coisa foi, então, trazida a presença por uma forma de experimento de causalidade, como objeto para representação.

O pensamento filosófico acaba por ser uma metamorfose desse tipo de pensamento, do modo de representação científico/ lógico. A coisa é trazida à presença constante como objeto de representação. O seu objetivo é captar o objeto tal como ele é, seu modo de desvelamento, ela provoca, interpela a coisa a mostrar-se de acordo com suas experiências e teorias, dominando o ser da coisa, representando.

O trabalho científico tem por pretensão ser uma elaboração do real, tendo por métodos os cálculos e se especializando em áreas compartimentadas. O pensamento calculador se tornou norma de pensamento unidimensional da ciência moderna e da técnica cuja essência é a Ge-stell. Essa, por sua vez, como abordada por Heidegger é distinta de uma concepção comum de técnica como meio de fazer algo meramente instrumental para chegar a um fim.

A técnica para Heidegger é também um modo de desvelamento. É nesse desvelar da técnica que a mesma mostra sua essência em algo que designamos especificamente de técnica moderna, para determinada época, ela não mais é uma produção em sentido grego de techné, é de fato um desvelamento, mas sob forma de provocação.

$\mathrm{Na}$ interpelação (Ge-stell) a natureza é convocada/ forçada a responder. Ela nada mais é do que uma reserva de forças, de energia. O modo de desvelar como interpelação é característico dessa técnica moderna em face aos fundos disponíveis da própria natureza, tudo que é presente se torna um grande estoque.

O próprio homem é interpelado a exigir da natureza, é reivindicado a interpelar a natureza como objeto de observação de pesquisa e controle. Ge-stell, o apelo provocante, põe o homem na tarefa de interpelar tudo como fundo disponível. Essa é a essência da técnica moderna e daí deriva a ciência moderna e seu pensamento científico.

Heidegger mostra que cronologicamente, do ponto de vista historiográfico, a ciência moderna da natureza precede ao aparecimento pleno da técnica moderna. Porém, a própria cronologia não fornece necessariamente um acesso à verdade de que a ciência moderna é parte dessa essência da técnica que já previamente aparece. A técnica não é consequência de um processo anterior, no caso das ciências das naturezas, pois já está presente nelas sua essência. O pensamento calculador lógico advindo não é necessariamente pensamento com números, todavia uma modalidade de pensamento específico da técnica moderna que se delineia, é uma condenação a contar, garantir e dominar. 
O tipo de pensamento calculador tem como características: (i) a valorização da lógica, (ii) a representação, (iii) efeitos de causa e consequência, (iv) conceitos e teorias, (v) exatidão. O pensamento técnico se resume ao cálculo (rechnen) e controle, todo pensamento que conta é um cálculo. Só por representar ele já conta, como põe também MarlèneZarader em Heidegger e as palavras de origem (ZARADER, 1990), é perseguir e garantir o real para si.

O primeiro a surgir dentro do pensamento calculador é o entendimento conceitual, constituindo como uma agressão ao próprio real, o qual é interpelado para mostrar-se a partir e dentro da representação do conceito. O real é calculado de forma prévia para garantir a dominação dos resultados das experiências científicas decorrentes, a natureza é posta sob a luz da lógica matematizante. A natureza vista como reserva de matéria-prima vem de encontro de modo unidimensional, em uma relação binária sujeito/ objeto.

O mundo nada mais é aquilo que é requerido pela razão, pelo pensamento calculador racionalizante, uma real agressão contra o real, que a tudo quer dominar e assegurar na apreensão representativa. Essa vontade de dominação é um pensamento de via única regido pela técnica onde reina o esquecimento da própria linguagem, da poiesis.

A linguagem ,para Heidegger,é o local onde habita o ser. É preciso, então, reconduzir o homem ao seu elemento essencial originário, estar aberto para o acolhimento do ser. Um caminho meditativo, um longo caminho que foi encoberto. Retomar o pensamento é levar a seu lugar mais autêntico. Regressar para o mais próximo e ao mesmo tempo o mais distante.

Este pensamento não tem resultados úteis, é ao contrário inútil, não obsessivo com fins, diferente do mundo da técnica que mede eficiência e ganhos. Para Heidegger, medir o pensamento do ser pela sua eficácia é 'entificar', "medir pela bitola do ente". O pensamento meditativo não pode ser medido por questões de utilidade, deveria ter como sua única tarefa não a perseguição e controle, mas a escuta ao ser e abertura para o mistério.

A concepção metafísica do homem como animal racional o coloca em um domínio meramente biológico reducionista, ou ainda, como sujeito, Cogito. Na ausência de pátria do homem a ciência moderna põe tudo como reserva calculável, em uma realidade objetiva e constantemente presente, tudo é reduzido ao objetivo e verificável, tido como universalmente e logicamente válido. Como exemplifica bem Heidegger um rio não é mais um rio, porém fonte de reserva para o turismo, o comércio ou fonte de energia. É uma visão bem diferente do rio tido pelo poeta Hölderlin, ao poetizar sobre o rio Reno. O poético passou a ser visto não como fazer aparecer, fundação e lar da verdade, mas como o que está distante do verdadeiro, alheio à realidade, algo fantástico, fruto da imaginação da consciência.

Apenas a ciência é vista como possuidora do verdadeiro e válido conhecimento, porém não conhece a coisa em sua totalidade. O que a ciência calcula, conceitua e planeja sobre o rio não se configura, portanto, como a única visão exclusiva do mesmo, tampouco é a visão mais rica e fiel do rio. O perigo apontado por Heidegger em Serenidade (HEIDEGGER, 1959) se encontra nesse ponto o qual a análise científica se põe como a única via válida, como a única realidade estabelecida.

O ser humano reduzido ao biologismo e ao subjetivismo do psicologismo, onde a essência do homem é analisada de modo raso. O homem é posto nessa visão do projeto científico que, entretanto, se encontra em um caminho distante de esgotar o conhecimento total do ser. Heidegger aponta, então, a forma de habitar do homem também é no esquecimento, ele é uma constante já aí jogado no mundo, sua essência é verbal.

É necessária uma nova luz para o homem além do status de animal racional como objetivamente apreendido, onde se pretende esgotar todo o conhecimento e tudo pode ser cientificamente reduzido a 
uma fórmula. O ente passa a ser a todo momento verificável e válido universalmente. Todas as outras 'faces' do ente, como o poético de Hölderlin, não seria uma verdade própria do rio, mas uma criação estética imaginária e irreal do mesmo, a verdade de fato apenas seria entregue pelo conhecimento científico. Entretanto o rio da ciência e da técnica é apenas uma face da verdade do rio em sua totalidade.

Onde se encontra o perigo é no viés único do pensamento técnico que a tudo quer controlar, dominar e a tudo enxerga como reserva disponível. O homem enxerga seu papel como senhor dessa técnica, mas ele mesmo também é provocado a interpelar a natureza. Mas o homem não é senhor da técnica, nem sujeito, ela não é seu instrumento. Um caminho para superação é através do pensamento meditativo, da serenidade, ir em direção ao pensamento originário dos pensadores originários gregos Heráclito, Parmênides e Anaximandro.

Physispalavra chave do pensamento originário grego, remete à essência do próprio ser e da verdade. Significa literalmente crescimento. Em termos originários physisé brotamento, eclosão, fazer aparecer, eclodir e demorar no aberto. É ainda crescer na presença do aberto.Comumente a physisé atribuída a natureza, a seu brotar, ao desabrochar de uma flor, Heidegger interpreta de forma diferente esses pensadores originais, que põem que a physisé a própria presença que eclode no aberto, auto-surgimento.

Nos dois fragmentos de Heráclito para chegar à verdade. O fragmento 16 "Como alguém pode manter-se encoberto face ao que nunca declina?" e o fragmento 123 "A natureza ama encobrir-se". Ambos mostram o combate ambíguo da physis de desvelamento e velamento perpétuo, o ente em sua totalidade que mantém o mistério (Gebeimnis).

A tensão entre ocultação e des-ocultação do ser no aberto é mostrado à essência da própria physis. Primeiro eclode o ente, Aufgehen, mas ele não é pura emergência, como põe o fragmento 123 de Heráclito a physis ama encobrir -se, não é tida de imediato para os homens, muito menos se esgota. Ela tende a ocultar-se, a natureza ama se ocultar.

Physis é a própria eclosão do ser que se opõe à ocultação, sempre desabrochando, no entanto não exclui seu velamento, que é fundamental para seu próprio eclodir. No fragmento 16, Heráclito nos mostra o conflito entre ocultação e des-ocultação, no fragmento 123 a physis ama esconder-se. A interpretação mais comum está em entender physis como natureza. Para Heidegger não é necessariamente o que Heráclito põe, não fala sobre uma dificuldade de acesso, mas que alheio a isso ela ama encobrir-se.

Aquilo que nunca declina, oculta-se ama encobrir-se. O que parece se auto contradizer em si mesmo em termos lógicos, revela que a lógica e o pensamento calculador não pode nunca atingir a verdade do ser. A lógica não é base para compreender o pensamento originário, seu desvelamento e velamento é uma unidade, o próprio ser é physis unidade de tensão entre velamento e desvelamento, emergência no aberto e ocultação para o mistério (Geheimnis) casa do ser.

\section{Referências}

HEIDEGGER, Martin. A questão da técnica. In: Ensaios e Conferências. Tradução de Emmanuel Carneiro Leão, Gilvan Fogel, Márcia Sá Cavalcante Schuback. Petrópolis: Vozes, 2001.

Ser e Tempo.Campinas: Editora Unicamp, 2012. 1200 p. Tradução de: Fausto Castilho.

Serenidade. Lisboa: Instituto Piaget,1959.

Sobre a essência da verdade. In: Conferência e escritos filosóficos. São Paulo: Editora Abril, 1973. 
STEIN, Ernildo. Uma Breve Introdução à Filosofia. Ujuí: Unijuí, 2002.

ZARADER, Marlène. Heidegger e as palavras da origem. Lisboa: Instituto Piaget, 1990.

Artigo recebido em: 23 de agosto de 2019

Artigo aceito em: 26 de dezembro de 2019 